\title{
Study on the strategy and its application in the interactive teaching of college English
}

\author{
Ge Liu \\ Bohai University, Jinzhou 121003, China; \\ lg781115@163.com
}

Keywords: Strategies; Interactive Teaching; College English; teacher-student interaction

\begin{abstract}
Interactive teaching, which can help students master the skills of language communication, increase the accumulation of language knowledge, and improve their ability to use language to express themselves has been extensively used in college English teaching. The low efficiency of traditional interactive teaching in most college English classes has received relatively little attention, however. In order to improve the efficiency of teacher-student interaction in college English classroom, it is necessary to further explore the theoretical basis of interaction strategies and study the further applications of the strategies in college English classes. In the present study, Firstly, the theoretical basis of classroom interaction strategies is explored. Secondly, based on many theories and studies, the related factors affecting classroom interaction between teachers and students in domestic college English teaching are discussed. Finally, the main methods to realize the teacher-student classroom interaction are presented. Practice has proved interactive teaching is beneficial to improve the teaching efficiency of college English course.
\end{abstract}

\section{Introduction}

The ultimate goal of college English teaching is cultivating the communicative and applied competence of students. Teachers have already paid more attention to the cultivation of students' communicative ability [1]. Interactive learning is a kind of creative and effective teaching theory and strategy to English learning which has widely adopted in many countries [2-3]. It is conceptually discussed using the strategies of Walker and Avant to promote a common understanding of interactive teaching and to clearly explicate the interactive teaching characteristics that will foster the construct validity of using interactive teaching in pedagogical research [4]. As one of the teaching activities, interactive learning is based on the cooperative interaction of learning groups. It is the cooperation and interaction between the dynamic factors of teaching system to promote learning in group performance as evaluation standard, achieves the teaching goal together. It is called "the most important and successful teaching reform in recent years" [5]. However, the low efficiency of traditional interactive teaching in most college English classes has received relatively little attention. It is necessary to further explore the theoretical basis of classroom interaction strategies and further study the applications of the strategies in college English classes to improve the efficiency of teacher-student classroom interaction. In the present study, firstly, the theoretical basis of classroom interaction strategies is explored. Secondly, the related factors affecting classroom interaction between teachers and students in domestic college English teaching are discussed based on many theories and studies. Finally, the main methods to realize the teacher-student classroom interaction are presented. Practice has proved interactive teaching is beneficial to improve the teaching efficiency of college English course.

\section{Strategies of interactive teaching}

Classroom interaction strategy refers to the English teacher through the design of vivid and interesting classroom teaching organization form to attract students into the classroom learning. Classroom questioning is one of the most basic ways to achieve interaction. Teacher questions in English class can be classified into two types, display and referential questions [6-7]. Display 
questions, or questions to which the English teacher knows the answers, require students to "display" their knowledge of comprehension, confirmation or clarification. Referential questions differ in that the answers are not already known by the English teacher at the time of asking e.g. "What are your interests?" or "What are your suggestions for maintaining a healthy lifestyle?"[7] In College English teaching, the problems can be divided into linguistic knowledge and content understanding. The former includes the meaning of words and phrases, and the analysis of sentence structure and grammatical rules. It is suitable to show the students' true knowledge of language by using the display problem. The latter involves text topics, discourse structure, genre and author point of view, and attitude, which are more suitable for reference. In the process of teaching demonstration and reference problems organically, can not only help students master the knowledge and cultivate students' analysis, judgment and reasoning ability according to the known information, which gives the logical answer [8]. After English teachers asked the question, he should wait for students to answer the question. Teachers should respond promptly to students' responses in the classroom, i.e., feedback, which is usually divided into two types: positive feedback and negative feedback. Positive feedback refers to the use of "Yes", "Good", "rage", "at" and other expressions to express the satisfaction with the students' responses. Negative feedback is to ignore the student's answer, criticism or eager to correct their mistakes, thus interrupting the student's answer. Positive feedback allows students to know that they have completed the task correctly, and also through the praise and affirmation students' self-confidence is increased and their interest in learning is also improved. Negative feedback leads to students dare not answer questions and are in a passive state in class, thus reducing their interest in learning and weakening their motivation to learn. Therefore, teachers should take active interactive methods to arouse students' enthusiasm for learning and enhance their interest in learning, so that students' language output ability can be improved [8-9].

\section{Main influencing factors}

\subsection{The mode of classroom teaching fails to embody the idea of student centered teaching}

Most of the English teachers in teaching design is still the traditional linear teaching from teaching to the individual, the process, focus on the analysis of the key and difficult point of teaching materials, and to impart knowledge and skills, ignoring the study survey and research has close relationship with the learning teaching contents, the teaching design focus on static grounding the display elements, the lack of students into dynamic, in-depth intervention. On the other hand, with the expansion of colleges, the number of students is increasing; the English teacher in large classes can only follow the traditional teacher-centered knowledge-feeding pattern, and teachers in the stage of explanation and training, analysis of the text, the students do written exercises in the audience to take notes. Teachers are the sole planners and operators of teaching activities, and students are in a passive position to accept knowledge.

\subsection{Students do not know enough about two-way communication in English class.}

Effective two-way communication in the classroom is an important guarantee for the English teaching. It can not only help students accept new knowledge and improve the skills, but also can realize the feedback function, and promote teachers flexibly adjust the teaching strategies, and provide the conditions for faster development of students. But many students are short of the communication awareness in the classroom, and even think that reading or class discussion is a waste of time. Therefore they show a variety of sloppy or reluctance. Although the multimedia teaching method has been widely used in English classroom teaching, and centered situation of English teachers has been greatly improved, it is difficult to cover up the reality of the existence of lively English class. The students are still in the position of passive acceptance of knowledge. 


\subsection{Disconnection between learning and application leads to the negative and passive of teaching and learning.}

Many students do not view classroom communication as a good way to improve their spoken English and acquire knowledge efficiently. In practical English teaching, most students are lack of creative learning activities, and they participate in classroom activities in order to complete the task or deal with the teacher's examination. They did not arouse their interest and desire. If students do not have the desire to participate in class activities, it is difficult to carry out an effective thinking, the knowledge they have just learned has not really been consolidated. Finally, the classroom English teaching is changed into teachers more speaking, and students practicing less. English teachers in the classroom speak wonderful, students are just container filled with knowledge, student's subjective initiative and creative thinking cannot be fully exploited.

\section{Main methods to realize the interaction teaching in class}

\subsection{Reforming traditional teaching modes and highlighting dominant positions of students}

The English teaching reform should be aimed at improving the comprehensive quality of students. The objectives should be cultivating the innovative spirit of students in addition to the basic skills. The necessary language skills should be trained and the comprehensive analysis of students' ability of language should be strengthened. At present, English classroom communication cannot really achieve the teaching effect due to cognitive problems. Interactive teaching can cultivate students' innovation consciousness, team consciousness and students' self-confidence, establish and develop entrepreneurial awareness of students [10]. Therefore, English teachers and students should reflect on the application skills of two-way communication in class. Teachers should take effective communication based on the learning desire of students in designing classroom teaching and highlighting the dominant positions of students in teaching practice.

\subsection{Well-designed classroom interaction to create enough space and time for students to practice and communicate in English}

The task-based teaching way of English curriculum requires teachers to correct and creative design of student activities, let students learn to use English, and complete the learning task through thinking, investigation, discussion, communication and cooperation. English teachers should actively provide students' autonomous learning and practice to create language environment, and combine the relevant activities scheme given in textbooks with the teaching contents. Meanwhile, the differences of students, the necessary requirements and demonstration should be taken into account. Students should exchange and guidance the activities.

\subsection{Constructing an evaluation system to promote the development of teachers and students}

The new curriculum of English requires teaching mode to emphasize the interaction of teaching and the autonomy of learning. This is formative assessment, which is an indispensable means of observing, evaluating and supervising the teaching process. Therefore, English teachers should build a teaching evaluation to promote the development of teachers and students for the purpose of the system. English teachers can understand the gap between teaching and learning by the means of operation of the teaching practice, stimulate students' intrinsic motivation, realized the teaching monitoring, incentive and evaluation from the outside to the inside and from passive to active. [11]

\section{Conclusions}

The ultimate goal of college English teaching is to cultivate the communicative ability and applied competence of students. Interactive teaching can consciously carry out two-way communication between teachers and students. It can help students be familiar with language communication skills, increase the accumulation of language knowledge, and improve students' ability to use language to express themselves. In this paper, the theoretical basis of classroom interaction strategies is firstly 
explored, and secondly the related factors affecting classroom interaction between teachers and students in college English classroom are discussed. Finally, the main methods to realize the teacher-student classroom interaction in college English classroom are also presented. Practice has proved that interactive teaching is beneficial to improve the teaching efficiency of the domestic college English course.

\section{Acknowledgement}

The author acknowledges financial support from the Education Science Planning of Liaoning Province in China (grand no.JG17DB021).

\section{References:}

[1] Jiang L, Liu M. Study on application of interactive approach in college English teaching [J]. Teaching English in China-CELEA Journal, 2006, 25(suppl 1):3847-3880.

[2] Ridley R T. Interactive teaching: a concept analysis [J]. Journal of Nursing Education, 2007, 46(5):203-209.

[3] Lee $\mathrm{C}, \mathrm{Xu} \mathrm{Y}$. Online, interactive learning of gestures for human/robot interfaces[C]//IEEE International Conference on Robotics and Automation, 1996. Proceedings. IEEE, 2002:2982-2987.

[4] Ridley R T. Interactive teaching: a concept analysis [J]. Journal of Nursing Education, 2007, 46(5):203-209.

[5] Yang F, Liu J, Zheng W J. The Exploration and Practice of Teaching Model for All-English Inorganic Chemistry [J]. Higher Education of Sciences, 2012.

[6] Brenda M. Wright. Display and referential questions: Effects on student responses 2016, 15(4)135-159.

[7] The Effect of Referential and Display Questions on Student Interaction in ESL Classroom[C]// In Gao, Dengliang, TESL in China, New current international Co. Ltd., 1992.

[8] Jiao Jiao, Jiang Tong Tong. The application and research of interaction strategy of teacher and student classroom in College English classroom. [J]. Jiannan literature, 2012(11):273-273.

[9] Tian X M. Affective factors and foreign language classroom teaching [J]. Journal of Huaibei Coal Industry Teachers College (Philosophy and Social Sciences), 2000, 21(2):149-150.

[10]Liu G. Enlightenment of teaching reflection on the professional development of College English teachers. [C] 2nd International Conference on Education, E-learning and Management Technology, Jul. 30-31, 2017, Xi'an, China.

[11]Yao L. J. Talking about the interactive problem of teacher and student at college English classroom. [J] Journal of HuBei TV University, 2008, 28(6):138-138. 